\title{
LAS ELECCIONES AUTONÓMICAS DE 25 DE MAYO DE 2003, EN LA CIUDAD DE MELILLA
}

JUAN JOSÉ LÓPEZ RODRÍGUEZ

Doctor en Derecho 


\section{SUMARIO}

1. Introducción. 2. AnteCedentes. 3. Las elecciones de 25 de mayo de 2003. 3.1. Resultados electorales. 3.2. Resultados comparativos. 4. Valoración.

SIGLAS UTILIZADAS.

CPM: Coalición por Melilla

CDS: Centro Democrático y Social

GIL. Grupo Liberal Independiente

IR: Izquierda Republicana

LV: Los Verdes

PIM: Partido Independiente de Melilla

PN RIF: Partido Nacionalista del RIF

PP: Partido Popular

PSOE: Partido Socialista Obrero Español

UPM: Unión del Pueblo Melillense

PGE: Presupuestos Generales del Estado.

TSJA:Tribunal Superior de Justicia de Andalucía 


\title{
LAS ELECCIONES AUTONÓMICAS DE 25 DE MAYO DE 2003, EN LA CIUDAD DE MELILLA
}

\author{
POR \\ JUAN JOSÉ LÓPEZ RODRÍGUEZ
}

Doctor en Derecho

\section{INTRODUCCIÓN}

La Ciudad de Melilla, a través de la Ley Orgánica 2/1995, de 13 de marzo, accedió a un régimen de autonomía peculiar en el que se integran elementos propios de las Comunidades Autónomas ${ }^{1}$, con rasgos característicos de los entes locales. El actual estatus no implica la desaparición del Municipio, sino que éste ha quedado subsumido en el nuevo ente autonómico. Consecuencia de ello es que el Presidente de la Ciudad ostente también la condición de Alcalde (art. 15) y que los miembros de la Asamblea posean, asimismo, la condición de Concejales (art. 7.2), teniendo asignadas la Cámara, además de la propias, las atribuciones que corresponden a los Ayuntamientos (art. 12.2).

El texto estatutario contiene diversas remisiones a la regulación local, tales como las referidas al régimen jurídico de su Administración lart.

1 El Presidente es nombrado por el Rey (art. 15) y las competencias atribuidas coinciden, en buena parte, con las de las CCAA (arts. 20, 21 y 22), aunque la Asamblea no dispone de capacidad legislativa sino de potestad reglamentaria, en los términos que establezca la legislación general del Estado (art. 21.2). También la Cámara tiene atribuida capacidad de iniciativa legislativa (art 13), pero no dispone de la facultad para designar Senadores ni de legitimación ante el Tribunal Constitucional. 
30) y al del personal propio de la Ciudad (art. 31); al régimen financiero (arts. 34 y 40 ) y a las elecciones (art. 7.1).

En lo que se refiere a la ordenación de las elecciones, cabe señalar que el Estatuto melillense dispone que se regirán por lo establecido en la legislación estatal, reguladora del régimen electoral general, para la celebración de las elecciones locales. Esta remisión posibilita que sobre la base de lo establecido en el artículo 13.2 de la Constitución, en relación con el derecho de sufragio de los extranjeros, y en los artículos 176 y 177 de la Ley Orgánica del Régimen Electoral General, puedan participar en las elecciones autonómicas, como electores y elegibles, aquellos ciudadanos de la Unión Europea que sean residentes en la ciudad, así como los nacionales de otros países que hayan suscritoTratados con España sobre participación en las elecciones locales ${ }^{2}$.

\section{ANTECEDENTES}

La etapa autonómica melillense ha estado marcada por una sucesión de conflictos y de inestabilidad politica, con actos de transfugismo y reiteradas mociones de censura.

Las primeras elecciones a la Asamblea tuvieron lugar el día 28 de mayo de 1995, obteniendo el Partido Popular la mayoría absoluta, con 14 escaños de los 25 que componen la Cámara. Los restantes fueron para el Partido Socialista (5), Coalición por Melilla (4) y Unión del Pueblo Melillense (2). Pese a la mayoría obtenida por los populares, el mandato estuvo jalonado por numerosos sucesos, ya que en febrero de 1997 dos Diputados locales del PP dejaban la formación y se integraban en el Grupo Mixto para, posteriormente, suscribir una moción de censura con los Diputados del PSOE, de UPM y de CPM. En la sesión celebrada el día 1 de marzo no prosperó la censura, al ser impedido el voto a Palacios (uno de los populares disidentes), sobre la base de que el ahora candidato a

2 Hay que indicar que el Tribunal Constitucional (Declaración núm. 132 bis/1992, de 1 de julio, FJ 2C) ha señalado que la atribución a los no nacionales del derecho de sufragio en las elecciones a órganos representativos sólo podría ser controvertida si tales órganos ostentaran potestades atribuidas directamente por la Constitución y los Estatutos de Autonomía y que éste no era el caso de los Municipios. Sin embargo, cabe resaltar que si es el caso de la Ciudad de Melilla, ya que las potestades de sus órganos institucionales, al igual que las de los órganos de las CCAA, proceden directamente de la Carta Magna y del texto estatutario. 
Presidente había suscrito la moción debido a un interés personal o particular. Sin embargo, un año después, el 28 de febrero de 1998, continuó la sesión por resolución del TSJA y el Diputado que había sido recusado, pudo emitir su voto $y$ hacer prosperar la moción, accediendo asi a la Presidencia de la Ciudad.

Pero en este período, el PP había recuperado la mayoría en la Asamblea y procedió a plantear otra moción de censura contra el nuevo Presidente que no pudo prosperar ya que éste, mediante Decreto, dispuso su inadmisión y la no convocatoria del Pleno. EI TSJA estimó las pretensiones planteadas en el recurso interpuesto, declaró nulo el decreto presidencial y ordenó que se celebrara la sesión para debatir la moción formulada. Pero, en ese tiempo, el Grupo Popular habia perdido de nuevo la mayoría por otro nuevo acto de transfugismo, de modo que la moción no prosperó y el Gobierno de coalición, presidido por Palacios, continuó hasta el final de la legislatura.

En los comicios autonómicos del 13 de junio de 1999 se produjo la irrupción del GIL, que consiguió el mayor número de Diputados (siete), siguiéndoles CPM y PP, con cinco cada uno, la UPM y el PIM con tres, y el PSOE con dos escaños. El cabeza de lista de CPM, Mustafa Hamed, accedió a la presidencia con el apoyo del GIL y del PSOE, cuyos dos Diputados incumplieron las instrucciones de su partido de apoyar la candidatura de Juan José Imbroda (UPM). Tras una serie de vicisitudes, con frecuentes cambios en la composición del Ejecutivo, se configuró un Gobierno tripartito compuesto por CPM, GIL y PIM, que contaba con el apoyo de 15 Diputados, de los 25 que configuran la Cámara. Sin embargo, pocos meses después abandonaron sus respectivos grupos un miembro del PIM y dos del GIL, ${ }^{3}$ lo que posibilitó que, en el mes de julio, se presentara una moción de censura contra Mustafa Hamed, suscrita por el resto de las formaciones políticas (PP, UPM, PSOE) y los disidentes referidos, en la que se incluía como candidato a la presidencia a Juan José Imbroda. Pese a los intentos de impedir la celebración del Pleno, finalmente se celebró, prosperando la moción formulada.

A partir del acceso a la Presidencia de Imbroda, se inicia una etapa de estabilidad política, recuperándose la conexión con el Gobierno Central que, con la presencia del GIL en el Ejecutivo autonómico, se había visto notoriamente afectada.

3 Posteriormente otros tres Diputados del GIL disidentes se pasaron también al Grupo Mixto apoyando al Gobierno Imbroda hasta el final del mandato. 


\section{LAS ELECCIONES DEL 25 DE MAYO DE 2003}

A los comicios autonómicos de 2003 concurrieron ocho formaciones políticas: Partido Popular-UPM (en coalición electoral), Coalición por Melilla, Partido Socialista Obrero Español, Partido Independiente de Melilla, Centro Democrático y Social, Izquierda Republicana, Los Verdes, y el Partido Nacionalista del Rif.

La decisión de la dirección nacional popular de que el upemista Imbroda encabezara la lista electoral conjunta, causó ciertas tensiones en determinados sectores del PP local que, finalmente, fueron reconducidas. En el PIM se produjo una escisión con el abandono del partido de la entonces Diputada Iglesias, quien acabaría presentándose como cabeza de lista por el CDS.

La campaña electoral puede calificarse de limpia, sin que se produjeran incidencias destacables.

\subsection{Resultados electorales}

Los resultados obtenidos por las distintas formaciones políticas fueron los siguientes:

\begin{tabular}{|l|c|c|c|}
\hline & Número de Votos & Porcentaje $^{4}$ & Número de escaños \\
\hline PP-UPM & 15.440 & 55,62 & 15 \\
\hline CPM & 7.392 & 26,63 & 7 \\
\hline PSOE & 3.365 & 12,12 & 3 \\
\hline PIM & 739 & 2,66 & 0 \\
\hline CDS & 417 & 1,50 & 0 \\
\hline LOS VERDES & 165 & 0,59 & 0 \\
\hline IR & 139 & 0,50 & 0 \\
\hline PN RIF MELILLA & 101 & 0,36 & 0 \\
\hline
\end{tabular}

(Cuadro elaborado a partir de los datos facilitados por la Delegación del Gobierno en Melilla)

4 Calculado sobre los votos totales a candidaturas. 
- Número de ciudadanos con derecho a voto

- Abstención $20.960(42,61 \%)$

- Votos emitidos $28.229(57,39 \%)$

- A candidaturas

- En blanco 315

- Nulos 156

Cabe destacar la contundente victoria obtenida por la coalición PPUPM, que obtuvo 15 escaños, lo que supone el mayor número de DiputadosConcejales logrados por una lista electoral en los 3 comicios autonómicos, asi como en las elecciones municipales celebradas desde $1979^{5}$.

\subsection{Resultados comparativos sobre los distintos procesos electorales autonómicos.}

\begin{tabular}{|c|c|c|c|}
\hline & Autonómicas 1995 & Autonómicas 1999 & Autonómicas 2003 \\
\hline Número de electores & 42.820 & 47.386 & 49.189 \\
\hline Número de votantes & $\begin{array}{r}26.432 \\
(61.73 \%) \\
\end{array}$ & $\begin{array}{r}28.638 \\
(60,44 \%) \\
\end{array}$ & $\begin{array}{r}28.229 \\
(57,39 \%) \\
\end{array}$ \\
\hline Abstención & $\begin{array}{r}16.388 \\
(38,27 \%) \\
\end{array}$ & $\begin{array}{r}18.748 \\
(39,56 \%)\end{array}$ & $\begin{array}{r}20.960 \\
(42,61 \%) \\
\end{array}$ \\
\hline Votos válidos & 26.322 & 28.544 & 28.073 \\
\hline Votos en blanco & 265 & 297 & 315 \\
\hline Votos nulos & 110 & 94 & 156 \\
\hline Votos a candidaturas & 26.057 & 28.247 & 27.758 \\
\hline $\begin{array}{l}\mathrm{N}^{0} \text { de escaños y } \% \\
\text { de votos logrados }\end{array}$ & $\begin{array}{l}\text { PP (14) } 47,68 \% \\
\text { PSOE (5) } 20,08 \% \\
\text { CPM (4) } 15,63 \% \\
\text { UPM (2) } 10,00 \%\end{array}$ & $\begin{array}{l}\text { PP (5) } 18,90 \% \\
\text { PSOE (2) } 9,47 \% \\
\text { CPM (5) } 20,65 \% \\
\text { GIL (7) } 26,20 \% \\
\text { UPM (3) } 11,53 \% \\
\text { PM (3) } 10,41 \%\end{array}$ & $\begin{array}{l}\text { PP-UPM (15) 55,62\% } \\
\text { PSOE (3) } 12,12 \% \\
\text { CPM (7) } 26,63 \%\end{array}$ \\
\hline
\end{tabular}

(Cuadro comparativo elaborado a partir de los datos facilitados por la

Delegación del Gobierno de Melilla)

5 No obstante, hay que tener en cuenta que, en 1995, si se sumaran los escaños obtenido por las dos formaciones PP y UPM - catorce y dos respectivamente - se alcanzaría el número de 16. 


\section{VALORACIÓN.}

En los resultados del 25 de mayo de 2003, al parecer, incidieron varios factores. Uno de ellos es la estabilidad política lograda por el Gobierno Imbroda, en la segunda parte de la legislatura anterior, y el alto grado de conexión con el Ejecutivo Central quien, tras la experiencia derivada de la presencia del GIL en Ceuta y Melilla, ha puesto en marcha una política de inversiones, con un notabilísimo incremento de las dotaciones consignadas en los PGE y un programa de actuaciones para el desarrollo socioeconómico de la ciudades norteafricanas, proliferando las visitas institucionales, especialmente las realizadas por los responsables de distintos departamentos ministeriales. Un factor también decisivo ha podido ser la firme actitud del Gobierno Aznar en la crisis del islote Perejil, que ha derivado en una mayor seguridad ante las continuas reivindicaciones de ambas ciudades por el reino alauita 6 .

Asimismo, merece reseñarse el escaso apoyo en las urnas obtenido por el PSOE, que sólo logró 3 Diputados. Aunque supone un incremento respecto a los representantes obtenidos en los anteriores comicios, puede calificarse de resultado escaso y, en parte, inesperado, debido al aumento que en general han experimentado los socialistas a nivel nacional 7 .

Mención destacada merece CPM, que obtuvo el $26,63 \%$ de los votos emitidos. Este partido localista ha experimentado una evolución progresiva desde que en los primeros comicios autonómicos obtuviera 4 escaños, ya que en las elecciones siguientes consiguió 5, para llegar a los 7 en las recientes de mayo de 2003 , lo que supone la mayor representación obtenida nunca por una formación de carácter local, tanto en elecciones autonómicas como municipales, en Melilla. Su apoyo mayoritario proviene de los ciudadanos de etnia bereber, lo que se evidencia por el hecho de que, en los colegios electorales ubicados en zonas donde residen fundamentalmente miembros de este colectivo, el dominio en las urnas de los cepemistas fue notorio8.

6 En Ceuta, los populares lograron 19 de los 25 escaños en las elecciones autonómicas del 25 de mayo.

7 También en Ceuta el PSOE obtuvo un resultado corto, logrando únicamente 2 escaños y el $8,7 \%$ de los votos.

8 En el Colegio Juan Caro, CPM obtuvo 1559 votos frente a los 340 de PP-UPM; en el Colegio León Solá 1.090 por sólo 324 del PP-UPM; en el IES Rusadir 963 frente a 717 ; y en el C.P. Mezquita 667 de CPM por 233 de los populares y upemistas. 
Puede señalarse, asimismo, que se ha producido una menor fragmentación en los escaños disputados, concentrándose el voto en tres formaciones políticas, contrastando con los comicios de 1999 que duplicó el número de partidos que obtuvieron escaño. Parece que Melilla ha optado por la estabilidad.

En cuanto a la abstención, si bien se produjo un incremento teórico del $4,25 \%$ y del $3,03 \%$ con respecto a los comicios de 1995 y de 1999, debe tenerse en cuenta que para el cálculo del índice de participación en las elecciones de 2003 se han incluido los votos de los emigrantes, cuya participación fue tan sólo del 0,38\% (11 votos sobre 2.882). En las elecciones anteriores se contabilizaban separadamente, por lo que de haberse seguido este sistema el porcentaje de abstención de.2003 hubiera sido el mismo de 1999.

En definitiva, las elecciones autonómicas de 2003 han deparado un marco dominante de la coalición PP-UPM, la consolidación como segunda fuerza política de CPM, que sigue en progresión ascendente, la escasa recuperación del PSOE y la desaparición del GIL y del PIM, que en la primera etapa de la anterior legislatura formaron parte del Gobierno de coalición encabezado por el cepemista Mustafa Hamed. 